\title{
Da perdição à esperança: Terra-pátria 14 anos depois
}

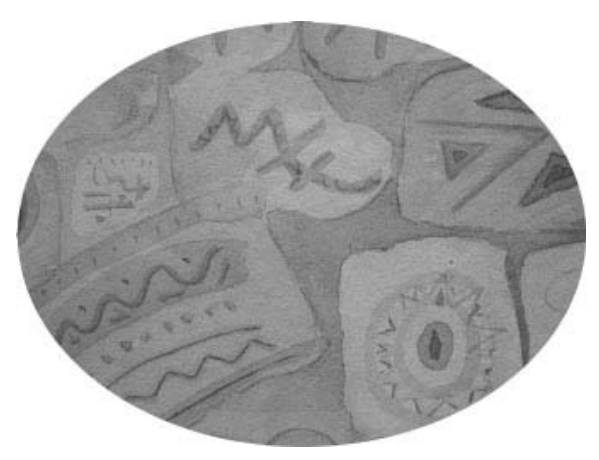

Edgard de Assis Carvalho*

\section{Resumo}

Em Terra-Pátria, ensaio publicado em 1993, Edgar Morin (Morin, 1993) enfatizava a necessidade de uma reforma do pensamento capaz de conceber as coisas em seu contexto e definir a comunidade do destino terrestre. Diante da crueldade do mundo, da ampliação de fanatismos, ódios, desigualdades, intolerâncias, cabe perguntar se, neste ano de 2007, a esperança na comunidade do destino terrestre é algo realizável ou um argumento utópico, uma idealidade sem condições biopolíticas de concretização.

Palavras-chave: Edgar Morin. Antropologia. Educação. Sustentabilidade. Complexidade.

\begin{abstract}
On Terra-Pátria, essay published in 1993, Edgar Morin emphasized the need for reform of thought capable of conceiving things in their context and set the Land destination community. Given the cruelty of the world, the expansion of fanaticism, hatred, inequality, intolerance, one wonders if in this year 2007, the hope the earth destination community is something feasible or an utopian argument, an ideality without any biopolitical conditions of coming into being.
\end{abstract} *Professor titular de Antropologia da Pontifícia Universidade Católica de São Paulo (PUCSP), Coordenador do Núcleo de
Estudos da Complexidade (Complexus), da mesma universidade. 

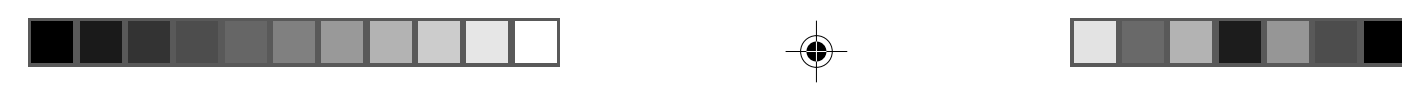

Keywords: Edgar Morin. Anthropology. Education. Sustainability. Complexity.

Em Terra-Pátria, ensaio publicado em 1993, Edgar Morin (MORIN, 1993) enfatizava a necessidade de uma reforma do pensamento capaz de conceber as coisas em seu contexto e definir a comunidade de destino terrestre. Diante da crueldade do mundo, da ampliação de fanatismos, ódios, desigualdades, intolerâncias, cabe perguntar se, neste ano de 2007, a esperança na comunidade de destino terrestre é algo realizável ou um argumento utópico, uma idealidade sem condições biopolíticas de concretização.

A recuperação da vida só se efetivará se conseguirmos exercitar a solidariedade. Para redescobri-la é preciso consumar e manter o diálogo ativo e permanente. Para dialogar, é necessário que as partes envolvidas suspendam, mesmo que temporariamente, suas crenças, pressupostos e preconceitos, para que a comunicação e o fluxo das ideias se efetive e se movimente. Ao observarmos nosso cotidiano escolar, familiar, político, amoroso, constatamos que perdemos essa condição ética. Vivenciamos, sim, um diálogo de surdos, em que uma parte quer fazer valer, a qualquer custo, seus pontos de vista, quaisquer que sejam eles.

Um efetivo diálogo de solidariedades deve, portanto, fazer comunicar, pôr em movimento e em simbiose todos os componentes da sociedade-mundo planetária: ricos e pobres, excluídos e incluídos, alfabetizados e analfabetos, homens e mulheres, heteros e homossexuais, cientistas e poetas. O objetivo mais amplo dessa rede implica a transformação das estruturas de dominação, exploração, desigualdade e exclusão hoje dominantes no comando da Terra. Apesar da visibilidade de injustiças, intolerâncias e ódios, o caráter da revolta permanece homeopático e bem-comportado demais.

A solidariedade de que falo aqui diz respeito a nossa responsabilidade éticopolítica diante da violência do capitalismo global e do caráter abjeto de seus efeitos sobre milhões de pessoas a quem subjuga sem distinção de latitude ou longitude, norte ou sul. Slavoj Zizek (2003), filósofo, esloveno, pensador radical defende a ideia de que a política deve ser sempre "politicamente incorreta", ou seja, concentrar-se na crítica dos princípios organizatórios do capitalismo liberal global. A violência político-discursiva do capital é de tal monta que os "estarrecidos do planeta", expressão de Jan Patocha (Patocha, 1998) que designa o estado do mal-estar planetário, devem procurar subverter excessos ingovernáveis e investir na busca de um universalismo político capaz de dialogizar igualdade e liberdade.

12 Somanlu, ano 9, n. 1, jan./jun. 2009 
Como ponto de partida, três princípios, ou bases para o diálogo precisam ser construídos e assumidos por todos: Sustentabilidade, Responsabilidade e Esperança. Constituem ideias-guia cuja função é impregnar o cenário planetário, superar o sentimento de impotência, deflagrar uma ecologia da ação voltada para a regeneração biocultural.

Afirma-se que uma sociedade é sustentável quando as gerações presentes empenham-se em garantir para as futuras a satisfação de necessidades básicas e níveis de vida íntegros e dignos. Esse pressuposto implica o entendimento da Terra como um sistema autorregulador que mantém o equilíbrio necessário para a continuidade e preservação dos organismos vivos. Em consequência, seria estranho que um mundo voltado para a sustentabilidade elegesse como prioritários o crescimento econômico e a dominação da natureza.

O primeiro passo a ser dado para enfrentar esse desafio reside na alfabetização ecológica em todos os níveis da educação, do ensino fundamental à universidade. Tal iniciativa requer uma mutação na compreensão da cultura. Conceito-armadilha para Edgar Morin, a cultura é o centro nervoso da vida, práxis cognitiva planetária cuja origem remonta à filogênese e à ontogênese da espécie. Essa pedagogia complexa articula modalidades lógico-racionais a expressões mítico-imaginárias. Em outras palavras, razão, determinação, repetição e objetividade não sobrevivem sem sensibilidade, incerteza, criatividade e subjetividade.

O sujeito nunca permanece inerte, transcendente, diante do objeto; em decorrência disso, nas práticas do dia a dia, modalidades arlequinadas de subjetivação articulam-se a múltiplas topologias de objetivação regidas pelas relações de oposição e complementaridade. Seres humanos que somos, estamos sempre prontos, e aptos, a desenvolver, recriar e reorganizar modalidades existenciais diante de um mundo real cada vez mais plural, globalizado, efêmero.

"O mundo precisa ser mais feminino", slogan muito repetido em reuniões de ecologistas, não é uma palavra de ordem inútil, panfletária, mas algo apropriado para fundamentar a ideia de um mundo menos androcêntrico e arrogante. Ser alfabetizado ecologicamente implica preservar nosso lar-terra de qualquer tipo de agressão, venha de onde vier. Todos os componentes desse lar, como se fossem os de nossa própria casa, encontram-se inter-relacionados, cada parte se junta com a outra. Constituem, portanto, um sistema, mesmo instável, caótico e indeterminado. Assumir que ecossistemas naturais e culturais regem-se por princípios de organização semelhantes, 
implica entendê-los como elementos de uma rede solidária, plural, complexa. No mundo vivo nada se perde. O que sobra e se desorganiza de um lado, reaparece e se reorganiza do outro. Essa é a marca indelével da evolução de todos os organismos vivos.

Vida e morte não se negam, sempre se complementam, onde quer que nos encontremos, no plano material ou espiritual, físico ou metafísico. Se podemos acreditar, com certo grau de certeza, que o início da vida ocorreu há três bilhões de anos, a continuidade que hoje presenciamos foi, certamente, produto de uma ampla cooperação entre espécies naturais e humanas. Por isso, a imagem da competição sangrenta pela sobrevivência deve ser substituída pela parceria pacífica em prol da continuidade, da preservação, da construção de valores éticos e universais.

Responsável por uma visão da criação que não fica nada a dever às pretensões científicas, os ensinamentos da sabedoria tibetana (1988) tornam-se fundamentais para uma reflexão aberta desprovida de ressentimentos. A Terra, narra um conto apócrifo, emergiu como uma montanha, e ao redor de seus picos o vento sussurrava incansável, formando uma nuvem atrás da outra. Das nuvens caiu mais chuva, mas, desta vez, mais forte ainda e carregada de sal; daí se originaram os grandes oceanos do universo. O centro do universo é uma montanha de quatro caras, feita de pedras preciosas e cheia de coisas maravilhosas com muitas espécies de árvores, frutos e plantas. A montanha é também a morada dos deuses e dos semideuses.

As conexões entre natureza e cultura são mais do que evidentes na narrativa acima resumida. Transpô-las para o plano da sustentabilidade planetária requer a eleição de prioridades. É quase certo que o desenvolvimento e a velocidade da tecnologia terão de ser repensados, sem que isso envolva qualquer tipo de retorno à idade da pedra. O caráter prometeico da ciência precisa ser criticado, relativizado mesmo, para que a sustentabilidade deixe de ser um mero discurso oportunista de estados cínicos e passe a governar sentimentos e ações de todos. Todos sabemos o preço que o titã Prometeu pagou por ter roubado o fogo do Olimpo e ensinado aos homens a empregá-lo.

Algumas perguntas dirigidas a todas as sociedades poderiam representar um bom ponto de partida para que nos conscientizássemos dessa necessidade histórica. Todos os humanos poderiam retorquir se o excesso da tecnociência, a velocidade da comunicação, a estimulação do consumo propiciam estilos de vida mais integrativos, cooperativos e felizes para as atuais e futuras gerações.

14 Somanlu, ano 9, n. 1, jan./jun. 2009 
Formulado por Hans Jonas (JONAS, 1979), o princípio-responsabilidade é prioritário e inadiável. A responsabilidade deve impregnar não apenas indivíduos e nações. Organismos internacionais, instituições públicas e privadas poderiam, por exemplo, empenhar-se na construção de uma harmonia planetária que respeite simultaneamente a diversidade e a unidade dos processos civilizatórios sem esquecer que humanidade e animalidade constituem patrimônios histórico-culturais a serem preservados a qualquer custo.

Tornar-se responsável envolve necessariamente a visão de um futuro pacífico, a combinação de fatos com ideias, de palavras com coisas, de estratégias com ações, a proposição de uma cidadania planetária comum a todos. Mais que isso, exige educação ecológica constante, para que as novas gerações sejam alertadas dos perigos que as esperam e tomem consciência disso, mudando seus pontos de vista perante a vida pessoal e coletiva. Afinal de contas, a vida se constitui sempre de uma pluralidade de planos, vínculos, perspectivas, utopias.

Pode-se afirmar que a responsabilidade começou desde que o primeiro humano apareceu no planeta. Por vezes, exige que nos revoltemos e, simplesmente, deixemos de nos submeter ao que não achamos justo e prudente. Por outras, admite conciliações e, mesmo recuos, desde que não se perca de vista que nossa comunidade de destino, nossa Terra-Pátria, é algo inegociável. A responsabilidade se efetiva com a liberdade de fazer escolhas e tomar decisões que propiciem o bem-comum, a salvaguarda do equilíbrio dos sistemas naturais, a fraternidade de todos os povos e culturas.

Em seus Ensaios publicados em 1580, na cidade de Bordeaux, França, Montaigne (1533-1592) soube definir com precisão esse objetivo quando afirmou ser preferível ter uma cabeça bem-feita, ou seja, aquela capaz de religar e contextualizar, do que uma cabeça cheia, a que apenas amontoa conteúdos dispersos, que nunca se comunicam. (MONTAIGNE, 1987)

De nada adianta insistir no modelo da educação fragmentada, cujo marcador epigenético reside nas estruturas da repetição, mas, isso sim, buscar nas potências da criatividade, o exercício da autonomia incondicional do sujeito, a aceitação de que nossa qualidade de humanos, demasiado humanos talvez, nos faz responsáveis diante de nossos atos. Por onde começa a criatividade? Algumas iniciativas tentam reverter modelos institucionais de educação direcionando-os para objetivos complexos e sistêmicos. Mesmo que sua implantação seja sempre obstaculizada pelo sistema de crenças vigente, algumas delas merecem atenção. 
Ao topar coordenar o projeto da reforma do ensino médio francês nos estertores do finado século XX, que acabou por não se efetivar, assim como as iniciativas deflagradoras da Universidade do Mundo Real em Hermosillo, México, nesses anos iniciais do XXI, Edgar Morin deixa claro que a religação dos saberes e a reconstrução de meta pontos de vista sobre a vida, a terra, o cosmo, a humanidade, as culturas adolescentes e o próprio conhecimento constituem pontos de partida irrevogáveis para políticas acadêmicas da dita sociedade do conhecimento que nos aguarda (MORIN, 1999).

Naquela ocasião, mais precisamente em 1997, perguntaram ao poeta Yves Bonnefoy por que considerava fundamental o ensino da poesia nas escolas numa eventual reforma das condições do ensino fundamental. Sua resposta foi direta e incisiva. Disse ele que a poesia propiciava a prática da liberdade para com as palavras e a vivência da responsabilidade com um mundo melhor, com o sentido da vida.

Para o pensamento bom, encarnado, transparente, nômade, poesia e literatura constroem imagens amplificadoras, criam uma fantástica reserva de emoções, abrem janelas para o mundo, acionam níveis de realidade não percebidos pela linguagem monocárdica dos conceitos. Da mesma forma que o conceito de pássaro se explicita mais na modulação do canto, na riqueza das plumagens, nos mistérios do acasalamento do que em seu mero enquadramento numa ordem classificatória formal, quando se aprende um poema de cor, ou se lê um romance pela décima vez, essas narrativas permanecem para sempre em nossa mente como reserva de memória, fiéis companheiras que nos convidam a encarar a miséria do mundo de modo menos pessimista e a seguir em frente diante da irreversibilidade do tempo.

Ciência e imaginação, ciência e arte nunca se excluem, mas se complementam, empenhadas que estão em decifrar o sentido e o significado da vida. Não é mais possível que o século XXI mantenha a separação entre a cultura científica e a cultura das humanidades. Devemos, sim, navegar livre e democraticamente por todos os saberes que a cultura é capaz de colocar a nosso dispor, para que seja possível acessar a grande narrativa de todos os sistemas vivos. Pelas injunções da historialidade, nos tornamos seres esquecidiços - homo sapiens obliviosus - , ou seja, nos esquecemos de tudo e de todos, embora palavras, acontecimentos, mutações constituam marcas indeléveis da narrativa da vida (SERRES, 2005).

A recuperação dos mitos é crucial para retroalimentar o real, algo que só se efetivará pela transgressão das normatividades institucionais e pela potência da

16 Somanlu, ano 9, n. 1, jan./jun. 2009 
descoberta presente no imaginário radical. E por quê? Porque os mitos são auxiliares cognitivos que decifram sentidos ocultos recalcados, relembram tempos pretéritos, arcaicos, em que natureza e cultura viviam em simbiose, adiantam tempos futuros nos quais a felicidade, uma nova idade de ouro, voltará a reinar sobre a face da Terra. Resolvem contradições que a ordem vivida não sabe confrontar e, muito menos, solucionar. São operadores simbólicos que ampliam a criatividade, magmas complexos que rejeitam o caráter linear do tempo e do espaço.

É conveniente que mitologias antigas e modernas jamais sejam esquecidas e deletadas de nossa mente. Ao escutá-las no recôndito da alma, a resignação diante do óbvio e do efêmero passa a ser questionada. Distraídos pela informação e pelo mercado, esses dois paradigmas que regem o mundo das palavras e das coisas, vivemos de modo prosaico como se fôssemos adultos replicantes, damos as costas para as narrativas míticas, passando a entendê-las como elocubrações descerebradas de um mundo sem história, primitivo, outro. Integrantes do sistema-mundo, perdemos a identidade da terra-pátria, esquecemos o caráter transcendente de nossas temporalidades, mergulhados na mediocridade de um cotidiano cada vez mais pobre em significações cosmopolitas.

Para reverter esse quadro adverso e garantir uma possibilidade hominescente, um diferencial no processo de hominização, é necessário impor limites à racionalidade e à racionalização, à objetividade da verdade plena, assumir que o acesso ao conhecimento pode-se dar por múltiplas vias. Essa biopedagogia é essencial para a construção da responsabilidade intercultural e para a consolidação da esperança, terceira e última ideia-guia a ser explicitada.

Se, como vimos, responsabilidade e liberdade encontram-se intimamente ligadas, esperança e solidariedade constituem um par inseparável. Para se ter esperança é preciso colocar a mão na massa, cair na real sem se despregar do real-imaginário, ter vontade de mudar o status quo, não se deixar contaminar pelo sentimento de resignação, apatia e, muito menos, de passividade.

Em primeiro lugar, é preciso acionar as comportas da revolta, canalizando-a para os objetivos éticos da solidariedade. A constatação de quantos somos no planeta torna-se crucial: é fato irrevogável que já somos mais de seis bilhões de humanos, cifra que aumentará nas próximas décadas. Projeções estatísticas apontam que, em 2015, a população da Terra será superior a 7 bilhões de pessoas. Na época atual, cerca de 1,2 bilhões de pessoas sobrevivem com menos de um dólar/dia e outros 1,5 bilhões 
com menos de dois dólares. $80 \%$ do PIB mundial provém de 1 bilhão de pessoas que vivem nos países ricos. Os $20 \%$ restantes são divididos entre 5 bilhões de indivíduos que vivem nos países em desenvolvimento.

Sensibilizar-nos com essas cifras é um bom começo. Diante delas, a única esperança que resta a intelectuais exilicos consiste na tentativa de reverter esse quadro com argumentos comunicativos cujo conteúdo não pode ser objeto da censura prévia de quem quer seja, o que exige uma revolta programada dirigida aos detentores do poder.

É conveniente não esquecer que a palavra revolta pode significar interrogação, renovação, renascimento. Se meditássemos profundamente sobre esses três significados, poderíamos começar a gritar nas ruas, praças, em nossas casas e escolas: "Eu me revolto, logo nós somos", dístico criado em 1951 por Albert Camus (1913-1960)(GAY-CROSIER, 2002). A revolta é, simultaneamente, um sentimento individual e um anseio coletivo, algo que liberta nossa mente para ter esperanças de que nem tudo está perdido, de que somos capazes de pôr em movimento ações e atitudes cotidianas homininescentes, por mínimas que sejam, acionar armas de uma guerra civil pacífica contra desigualdades e exclusões. A vida simples e o pensamento autônomo não são horizontes intransponíveis, vazios, inalcançáveis. Basta olhar nosso entorno para nele identificar um sintoma do mal-estar, uma imagem crepuscular, uma projeção deformada de nós mesmos e, diante disso, partir para o confronto.

Originalmente formulado por Ernst Bloch $(\mathrm{BLOCH}, 1953)$ o princípio esperança é otimista e pessimista ao mesmo tempo. Otimista porque tem como horizonte um planeta em que as culturas passem a conviver e colaborar numa espécie de troca generalizada de seus modos de fazer, interagir, imaginar; pessimista, porque se sente impotente diante das condições e contradições da modernidade líquida, como se não soubesse por onde começar, ou mesmo contra quem se revoltar. É exatamente esse caráter ambivalente da esperança que anima todos os que situam na contracorrente dos dominadores, ao lado dos quatro bilhões de humanos que não usufruem dos benefícios mínimos da mundialização.

Por incrível que pareça, o Brasil, que sempre ocupa baixas classificações no que se refere ao desenvolvimento humano, não se sai tão mal no tocante à preservação de suas áreas verdes, anunciada em fóruns econômicos e sociais. Em dados de 2005, o Brasil passou a ocupar o $11^{\circ}$ lugar no índice de sustentabilidade ambiental - ISA -,

18 Somanlu, ano 9, n. 1, jan./jun. 2009 
medido pela combinação de 21 indicadores, dentre eles biodiversidade, qualidade do ar e da água, iniciativas para a redução de poluição, saúde e governança ambiental e participação em esforços internacionais colaborativos. Uma análise mais detida do ISA constata que são exatamente os países desenvolvidos que não contribuem adequadamente para a preservação e sustentabilidade da biodiversidade planetária. Abaixo de nós brasileiros figuram a França, os EUA, o Japão, os Emirados Árabes Unidos.

No sobe-e-desce dos índices, permanecemos num medíocre $72^{\circ}$ lugar no tocante à escolaridade, de acordo com dados da Unesco em 2006, melhoramos ligeiramente na preservação da natureza. Não nos animemos demais com cifras positivas, pois o Brasil conseguiu, nos últimos anos, destruir $70 \mathrm{mil} \mathrm{km}^{2}$ da floresta amazônica, sem falar da biopirataria, contrabandos de espécies animais e vegetais, concessões de zonas florestais pelo prazo de 30 anos a empresas privadas para exploração de terras, tudo isso sob o olhar complacente e conivente de governos, partidos e intelectuais.

Ao nos depararmos com o mapa do mundo, verificamos, com grande desapontamento, que as apregoadas metas do milênio previstas pela ONU estão longe de serem cumpridas. $\mathrm{O}$ acesso à água potável, à educação primária, à superação das mortalidades infantil e maternal, à extinção de pandemias como a Aids, a elevação do nível de vida (só na África subsaariana 44\% de pessoas vivem com menos de um dólar-dia) não se efetivaram. Os objetivos do desenvolvimento do milênio, - é sempre bom lembrar a sigla ODM - subscritos por 189 chefes de Estado do mundo inteiro, prescrevem o tempo - limite - 2015 - para a superação desses dados assustadores e vergonhosos. Uma mutação antropológica, não mais uma revolução histórica, é urgente para que a opulência e o liberalismo não se assenhoreiem do mundo da vida e conduza todos a uma fase terminal irreversível.

É verdade que pensadores independentes e transdisciplinares ousam dizer a verdade aos poderes instituídos, tentam mostrar-lhes que a utopia de um mundo novo não constitui tema exclusivo de poetas, romancistas e cineastas. Se só dispomos de palavras para prescrever nossas opiniões, nunca é tarde para reiterar que sustentabilidade, responsabilidade e esperança constituem um sistema aberto, abarrotado de brechas, bifurcações, desvios, dissipações. Um princípio não existe nem se efetiva sem o outro. Ancorados na trindade indivíduo-sociedade-espécie, inserem-se na tetralógica ordem-desordem-interação-organização. Constituem, também, formas de ação co- 
letiva voltadas para a reciprocidade e a solidariedade planetárias, a conscientização da humanidade comum, da Terra-mãe, pátria e morada de todos nós.

A criação da Unesco, em 4 de novembro de 1946, considerava prioritária a eleição de prioridades acautelatórias capazes de minorar o sentimento de mal-estar e a arquitetura da destruição decorrentes da Segunda Guerra. Naquele momento, o espectro do mal, a comoção mundial, a dor de Hiroshima e Nagasaki em 6 e 9 de agosto de 1845 punham de sobreaviso todos os humanos. Naquele momento trágico e dolorido, o extermínio de nós mesmos tornara-se visível, palpável.

Por um estranho paradoxo, sentimentos que favoreciam a compreensão dos povos, a colaboração das culturas passaram a germinar por toda parte, algo que os anos posteriores parecem ter esquecido para sempre. Sim, é possível concordar com a posição de Eric Hobsbawn de que a queda do muro de Berlim foi o ato terminal do século XX e que algo precisa ser feito aqui e agora.

A cultura do ódio bate cotidianamente à nossa porta. Medéia converte-se em nosso símbolo máximo. Ela, a banida, - assim como nós - expulsa dos muros da cidade, preferiu refugiar-se no infinito com sua carruagem alada e lá, talvez, voltar a ser alegre de novo. Como ela, a toda hora, rogamos por uma cidadania digna sem que os muros de nossas cidades, continentes e regiões nos expulsem para sempre de seu convívio.

Seres da falta e do excesso, nosso mundo é aqui mesmo. Somos objetos pequenos que sempre aguardam uma realização futura, sujeitos éticos com uma impressionante capacidade de suportar não apenas o sofrimento e a violência mimética, mas também de potencializar a resiliência, dar a volta por cima, redirecionar o sentido da vida, apesar dos pesares.

Por isso mesmo, nossa memória pode tomar de assalto a máquina do tempo e sintonizar as palavras ditas por Julian Huxley (1887-1975). Suas posições foram consideradas controvertidas, criticadas como conservadoras e até mesmo reacionárias. Especialista em genética e evolução, contrário a qualquer forma de racismo, árduo defensor do controle populacional e do planejamento familiar, soube definir com precisão os objetivos da Unesco. A ela caberia contribuir pela paz e zelar pela regeneração do homem. Valores universais inquestionáveis, precisam apenas impregnar e reeducar a mente de todos os habitantes do sistema Terra.

Fundado em representações coletivas, nosso mundo precisa impregná-los com a percepção real da experiência, estabelecer uma forte conexão entre representação de imagens e apresentação do mundo vivido. Como os indivíduos são agentes cria-

20 Somanlu, ano 9, n. 1, jan./jun. 2009 
dores da vida, nossos circuitos cognitivos de autocrítica e autopercepçâo têm de ser reativados, para que corpo e mente dialoguem de forma mais coerente.

Estar-junto, compartilhar, participar, solidarizar são pressupostos que fornecem sentido à recuperação da natureza e à utopia realizável de uma antropoética que religa pensamentos, intelectos e afetividades a dimensões individuais, coletivas, democráticas, cósmicas. O verdadeiro democrata, Mahatma Gandhi afirmou, "é aquele que, com meios puramente não violentos, é capaz de defender não apenas a sua liberdade, mas a de seu país e de toda a humanidade".

Como viver? Como ser feliz? Perguntas constantes que a todo momento devastam nossas mentes, obsessões que afligem nosso dia a dia pauperizado pela violência do capital que joga homens contra homens. Por isso, a revolta contra a inumanidade da história e dos males totalitários, fundada na ética da justiça perene constitui ponto de partida para deter o avanço crescente do individualismo, o declínio da moral, a sacralidade do Estado. Apenas a liberdade da compreensão intercultural pode trazer a paz. Diante disso, resta saber como definir nosso ser-no-mundo, como articular identidades individuais e identidades coletivas.

A identidade em si não é garantia de nada. Cria espaços topológicos endogâmicos que só reconhecem a si próprios, diferenças de diferenças e nada mais. A identidade pode matar desenfreadamente como afirmou recentemente Amartya Sen, Nobel de economia de 1988 (SEN, 2007). A produção da identidade é algo que exige a complementaridade crítica e não o antagonismo excludente. Esse último sempre mostra sua cara para além das fronteiras da tribo, da cidade, da nação, como considerou Claude Lévi-Strauss. O entendimento definitivo entre natureza e cultura exige auto-ética e autoreflexão para que a vida se reencante e o agir e o diálogo comunicativos se efetivem, socioética para que os outros não sejam meros artefatos da diferença, antropoética para que o anthropos contamine a todos.

Até quando o conhecimento continuará a não reconhecer que a distinção entre animalidade e humanidade precisa ser superada? Os animais pensam? Possuem razão? Desenvolvem cultura? Explicitam sensibilidades? Como enfatiza Fontenay (FONTENAY, 1998) o amor e o respeito pelos animais não conduzem à misantropia, ao racismo, à barbárie. Se a industrialização da sociedade faz com que a domesticação seja considerada necessária para garantir a sobrevivência dos humanos, hoje esses "campos de concentração" viram as costas para qualquer tipo de precaução que possa ser tomada para com o sofrimento alheio. 
O princípio da precaução, que sempre exige medidas acautelatórias a respeito de inovações tecnológicas, não rejeita os progressos da tecnociência; contém um conjunto de preceitos normativos bioéticos que, a cada dia, ganham visibilidade diante da inumanidade do conhecimento dito operacional, voltado exclusivamente para as leis do mercado. A utilização de primatas em experimentos, cujos resultados nem sempre são pautados pelo "respeito a todas as espécies vivas" é exemplo disso. A sociedade do espetáculo sempre aplaude esses prometeus pós-modernos locupletados com polpudas verbas de pesquisa que apregoam, a quatro ventos, soluções para a pobreza do mundo. Adeus qualquer resquício de humanismo! O que importa agora é a metafísica predadora que acomete animais e homens.

Mesmo quando fala da animalidade, a Filosofia não nos ensina nada sobre ela. E isso porque há um décifit de conceitos para tal. Para a Filosofia, criaturas animais são não-homens, não-humanidade, não-vida. Superar esse estado de coisas requer pontos de partida inegociáveis. Um deles diz respeito ao antropocentrismo, e isso porque, sabemos, desde Copérnico, Darwin e Freud, que a Terra não é o centro do universo, o homem não é o centro dele mesmo, porque resultante de extenso processo evolutivo; além desse duplo descentramento, somos atravessados pela linguagem do inconsciente que, a todo momento, nos projeta para horizontes impensados.

Feridos narcisicamente, não conseguimos fechar nossas chagas e permanecemos tributários de uma arrogância impune. Reassumir a universalidade da natureza e da cultura implica a redefinição do global-local, glocal para alguns, que nada mais é do que uma marchetaria construída por nossa pequena família mundial em meio a guerras, violências, consentimentos, dominações e alguns poucos momentos de paz.

Os animais e a natureza de modo geral nos são úteis para corroborar esse ponto de vista, ainda não assimilado em todas as suas consequências nos frios corredores da fragmentação dos saberes. A identificação continuada dos estados naturais tornará possível à condição humana pensar e refletir sobre ela mesma?

A pergunta exige explicitações. Se os animais servem para alimentar nossas projeções psíquicas, ao afirmarmos por exemplo, fulano é um asno, beltrano é astuto como uma raposa, escorregadio como uma cobra ou dissimulado como um sapo, como será que eles — os animais — nos vêem? Se é impossível que respondam a essa pergunta por serem destituídos de linguagem articulada, é forçoso reconhecer

22 Somanlu, ano 9, n. 1, jan./jun. 2009 
que sempre compartilham da vida dos humanos, mesmo depois que a domesticação e as experimentações laboratoriais impuseram-lhes sofrimentos descabidos.

Como acredita Cyrulnik (1998), uma Antropologia naturalista indica uma nova atitude do homem ante a linguagem e os demais seres vivos. Talvez essa Antropologia desempenhe as funções de uma fabulação viva, uma reordenação da convivência entre seres vivos que envolve ajuda-mútua, respeito, piedade, altruísmo, benevolência e, claro, muita prática democrática.

Desafio de nosso tempo, a nova desordem mundial produzida pelo capitalismo liberal global salta a nossos olhos nesses sete anos inaugurais do terceiro milênio. Exige a superação da guerra perpétua de todos contra todos, incita a extinção dos desmandos e intolerâncias da idade de ferro planetária, requer a luta indômita em prol de uma identidade futura baseada na sinergia entre plantas, animais e homens. Teremos que nos posicionar para além da natureza e da cultura (DESCOLA, 2005), sem deixar de interrogar e entender suas especificidades, para, sem voluntarismos proféticos, efetivar a colaboração das culturas, trilhar o caminho de coletividades complementares e multidimensionais, transmitir o patrimônio biocultural àqueles que virão depois de nós.

Não resta dúvida que a recuperação da natureza representa um bom começo para a efetivação desse horizonte incandescente, para que o tempo de nossas vidas não se perca para sempre nas brumas do passado, nos lamentos do presente, nas fugacidades do futuro. A noção de tempo, assumida em todas as dimensões por Marcel Proust (1871-1922) nos sete volumes de Em busca do tempo perdido (PROUST, 2002) deve adquirir valor cardeal, transmutar-se em fundamento da existência de todos, indivíduos, governos, instituições. Afinal de contas, sempre é tempo de recomeçar e encarar a vida como algo digno de ser realmente vivido, desfrutado, gozado.

Extremamente atuais, as conclusões de Edgar Morin em Terra-pátria recuperam a dialogia entre estado prosaico e estado poético, comportam uma missão racional e supraracional cujos objetivos seriam salvar o planeta, civilizar a Terra, restaurar a unidade humana, salvaguardar a diversidade. Nossa salvação pessoal, afirma ele, reside no amor e na fraternidade, nossa salvação coletiva consiste em evitar o desastre de uma morte prematura da humanidade, fazer da Terra que se encontra perdida no cosmo, nosso único porto de salvação. (MORIN, 1993) 


\section{Referências}

BLOCH, Ernst. Leprincipe espérance. Tradução de Françoise Wuilmart. Paris: Gallimard, 1976. [Edição brasileira: O princípio esperança. Tradução de Nélio Schneider. Rio de Janeiro: Contraponto, 2005]. 3 v. 19.

CONTOS POPULARES DO TIBETE. Tradução de Lenis Gemignani de Almeida. São Paulo: Editora Princípio, 1988.

CYRULNIK, Bons. Si les lions powvaient parler. Essai sur la condition animale. Paris: Gallimard/Quarto, 1998.

DESCOLA, Philippe. Par-delà nature et culture. Paris: Gallimard, 2005.

FONTENAY, Elisabeth de. Le silence des bêtes. La philosophie à l'epreuve de l'animalité. Paris: Fayard, 1998.

GAY-CROSIER, Raymond (ed.). L'bomme revolté, 50 ans après. Paris: Minard, 2002.

JONAS, Hans. Le principe responsabilité. Une éthique pour la civilisation techonologique. Tradução de Jean Greisch. Paris: Flammarion, 1995.

MONTAIGNE, Michel Eyquem de. Ensaios. Tradução de Sérgio Milliet, precedido de Montaigne - o homem e a obra, de Pierre Moreau. Brasília: Editora da UNB, $1987.3 \mathrm{v}$.

MORIN, Edgar. Terre-patrie. Paris: Seuil, 1993.

MORIN, Edgar Relier les connaissances. Le défi du XXe. siécle. Journées thématiques conçues e animés para Edgar Morin. Paris: Seuil, 1999. [Edição brasileira: Jornadas temáticas. A religação dos saberes: o desafio do século XXI/ idealizadas e dirigidas por Edgar Morin. Tradução e notas Flávia Nascimento. Rio de Janeiro: Bertrand Brasil, 2001].

PATOCHA, Jan. Liberté et sacrifice. Écrits politiques. Tradução de Erika Abrams. Grenoble: J. Milion, 1990.

PROUST, Marcel. Em busca do tempo perdido. Tradução de Fernando Py. São Paulo: Ediouro, 2002.

SEN, Amartya. La identidad pude matar. El País, domingo, 10 de junho de 2007.

24 Somanlu, ano 9, n. 1, jan./jun. 2009 

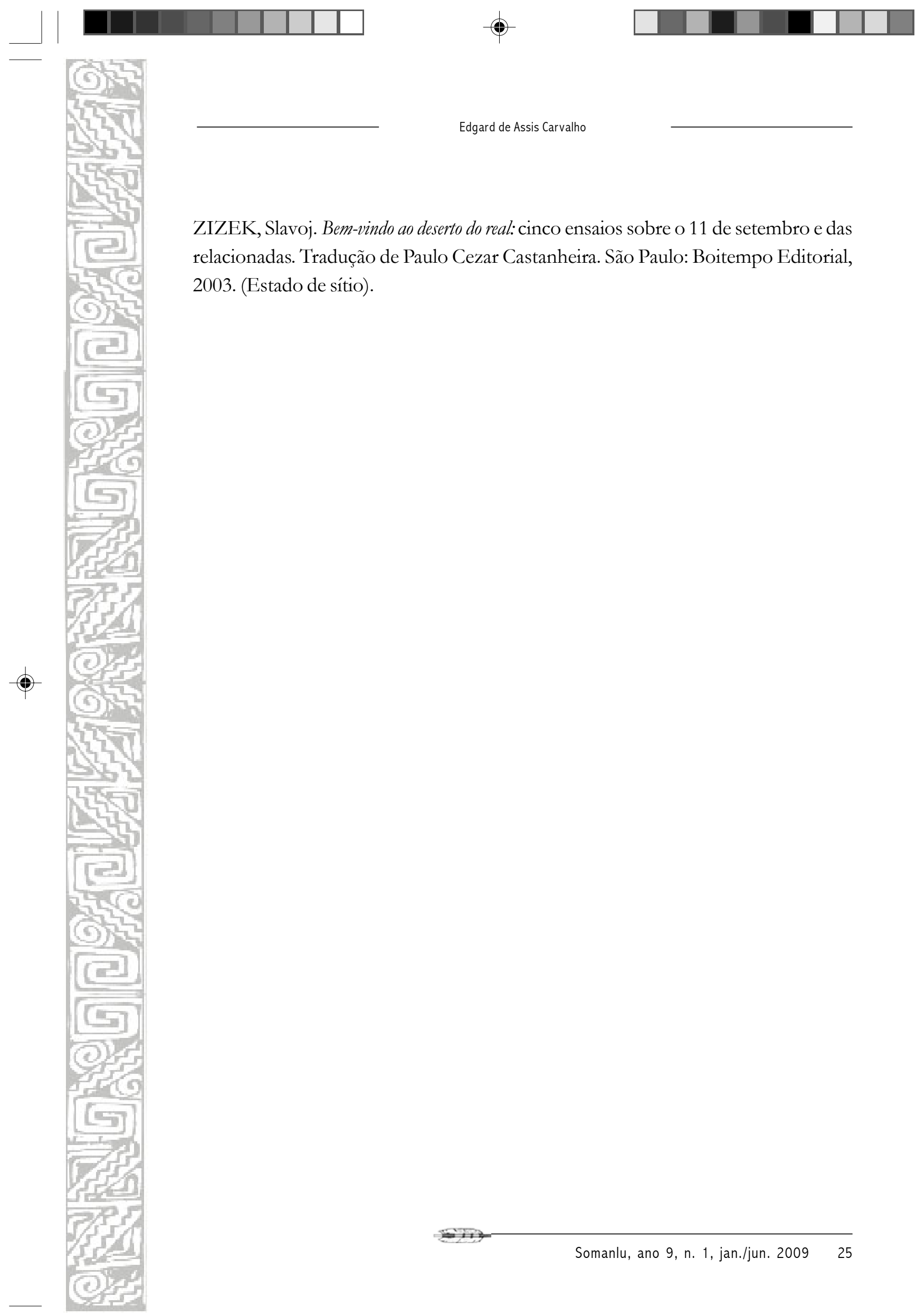

Edgard de Assis Carvalho

\begin{abstract}
ZIZEK, Slavoj. Bem-vindo ao deserto do real: cinco ensaios sobre o 11 de setembro e das relacionadas. Tradução de Paulo Cezar Castanheira. São Paulo: Boitempo Editorial, 2003. (Estado de sítio).

(1)

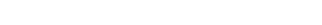

(2003. (Estado de sitio). 